\title{
EDITORES DE SUPLEMENTOS CULTURAIS E A INTELECTUALIDADE: SELEÇÃO, LEGITIMAÇÃO E CLASSIFICAÇÃO NA PRODUÇÃO DO CADERNO DE SÁBADO DO CORREIO DO POVO (PORTO ALEGRE, 1967-1981)
}

\author{
Cultural supplement editors and intellectuals: selection, legitimating and \\ classification in the production of Correio do Povo's Caderno de Sábado (Porto \\ Alegre, 1967-1981)
}

Editores de suplementos culturales y la intelectualidad: selección, legitimación
y clasificación en Caderno de Sábado de Correio do Povo (Porto Alegre, 19671981)

Everton Cardoso Professor do curso de Jornalismo da Unisinos e editor-chefe do Jornal da Universidade/UFRGS cardoso.everton@hotmail.com

\section{Resumo}

O Caderno de Sábado do Correio do Povo se constituiu como referência histórica entre os suplementos culturais brasileiros entre 1967 e 1981 ao abrir espaço para a circulação de ideias de intelectuais e para a construção de suas carreiras e posições. Este trabalho busca, a partir de dados categorizados na coleção por meio de Análise de Conteúdo, discutir o papel e a atividade dos editores do encarte, P. F. Gastal e Osvaldo Goidanich, protagonistas nessas dinâmicas. Com capital simbólico angariado por suas atuações no jornalismo e no campo da produção cultural, conseguiram tornar o suplemento ponto de confluência de trajetórias de indivíduos de perfis diversos e organizar uma rede que permite entrever agentes e instituições relevantes da cena local no período. Além disso, operaram um processo de estratificação cujos indícios estão contidos em recursos editoriais aplicados na montagem das edições.

\section{Palavras-chave}

Jornalismo cultural. Suplemento cultural. Editores

\begin{abstract}
Correio do Povo's Caderno de Sábado was a historical reference among Brazilian cultural supplements between 1967 and 1981 when it opened space for the circulation of ideas by intellectuals and for the construction of their careers and positions. This work seeks, based on data categorized in the collection through Content Analysis, to discuss the role and activity of the editors, P. F. Gastal and Osvaldo Goidanich, who had lead roles in those dynamics. With symbolic capital raised with their activities in journalism and in the field of cultural production, they managed to make the supplement a point of confluence of the trajectories of individuals of different profiles and to organize a network that allows to see relevant agents and institutions of the local scene in the period. In addition, they operated a stratification process whose evidence are seen in editorial resources applied in the assembling of editions.
\end{abstract}




\section{Keywords}

Cultural journalism. Cultural supplement. Editors

\section{Resumen}

El Caderno de Sábado de Correio do Povo es una referencia histórica entre los suplementos culturales brasileños entre 1967 y 1981 al abrir espacio para la circulación de ideas de intelectuales y para la construcción de sus carreras y posiciones. Este trabajo busca, a partir de datos categorizados en la colección a través de Análisis de Contenido, discutir el papel y la actividad de los editores, P. F. Gastal y Osvaldo Goidanich, centrales en estas dinámicas. Con el capital simbólico recaudado por sus actividades en el periodismo y en el campo de la producción cultural, lograron convertir el suplemento en punto de confluencia de las trayectorias de individuos de diferentes perfiles y organizar una red que permite ver agentes e instituciones relevantes de la escena local en el período. Además, operaron un proceso de estratificación cuya evidencia está contenida en recursos editoriales aplicados en las ediciones.

\section{Palabras clave}

Periodismo cultural. Suplemento cultural. Editores

\section{INTRODUÇÃO}

Desde que Caderno de Sábado, suplemento semanal de cultura do jornal Correio do Povo, deixou de ser publicado em sua primeira fase, em janeiro de 1981, restou nostalgia para a intelectualidade do Rio Grande do Sul. Expressão desse sentimento é o depoimento do poeta e professor Armindo Trevisan, colaborador assíduo da publicação que circulara por 14 anos: "Para mim, o desaparecimento do Caderno de Sábado foi um golpe. Tive a impressão de que, com ele, naufragou um projeto cultural. Depois dele vieram outros suplementos, mas nenhum dos 'substitutos' o substituiu verdadeiramente" (LOPES, 2014). A volta do nome em um novo encarte sabatino, em 2017, e a tentativa de ligar a versão mais recente à histórica não parece ter conseguido ocupar a mesma posição no imaginário local.

Ponto de confluência de trajetórias de parte significativa dos intelectuais locais entre 1967 e 1981, a publicação compôs e articulou a rede formada por esses agentes e pelas instituições integradas por eles. O Caderno de Sábado representa, dessa forma, a união de um grupo sob uma denominação específica, em sentido semelhante àquele que Sirinelli (1998) atribui às gerações ${ }^{1}$. Num processo dialético de pertencimento, portanto, associam-se grupo -

\footnotetext{
1 As noções de trajetórias, rede e geração são conceitos articulados por Sirinelli (1986; 1988; 1998) para descrever o processo histórico do campo intelectual. A primeira diz respeito a uma dimensão mais individual e inclui formação, afinidades ideológicas e filiações a agrupamentos ou instituições. Já a segunda tem caráter mais
} 
corporificado pelo encarte semanal - e indivíduos num intercâmbio de capital simbólico que os coloca em posições homólogas tanto no campo intelectual quanto no jornalístico. São, pois, referência histórica resultante de um processo de diferenciação por meio do qual se fizeram reconhecer.

Papel central na configuração desse projeto foi desempenhado pelos editores Paulo Fontoura Gastal - crítico de cinema de renome - e Oswaldo Goidanich - este último, com atuação no turismo e nas artes visuais, atuou regularmente até 1974, mas manteve proximidade com a redação mesmo depois do desligamento da empresa. Foram eles os responsáveis por selecionar, reconhecer e classificar aqueles que figurariam nas páginas do suplemento. Operaram, assim, processos semelhantes àqueles que acontecem no campo intelectual e que Sirinelli $(1986 ; 1988 ; 1998)$ designa como a tríade recrutamentoreconhecimento-estratificação.

O Caderno de Sábado, seguindo a tradição de publicações que o antecederam na função de fazer circular o pensamento e a produção artística ${ }^{2}$, constituiu-se como um aparato de comunicação que organizou as práticas dos letrados e, dessa maneira, transformou as ocupações dos intelectuais, os modos de competir por prestígio e posição e mesmo a relação desses sujeitos com o restante da sociedade (BRUNNER; FLISFISCH, 1983). O suplemento constituiu-se, no contexto dos anos 1960 e 1970, como lugar de transição de uma atuação mais diletante das gerações anteriores para práticas e posições institucionalizadas dentro do jornalismo (PEREIRA, 2011).

Ao cooptarem colaboradores para essas páginas, então, Gastal e Goidanich, de alguma forma, participaram da escrita da história da intelectualidade. Foram intelectuais que, ao atraírem para o projeto editorial que encabeçavam um conjunto de homens e mulheres de cultura que se identificavam com essa iniciativa, formaram uma rede ao seu redor, e esta restou como memória, tanto pelo documento que o $C S$ passou a constituir, quanto pelas lembranças a respeito da publicação e de quem a ela se ligou.

coletivo e pretende dar conta da teia de relações que se estabelecem entre esses sujeitos ao se organizarem dentro de um campo estruturado a partir de uma hierarquia decorrente de disputas por capital simbólico. A geração, então, estaria relacionada ao poder obtido por aqueles que alcançaram posições dominantes sobretudo a partir do reconhecimento de seus pares, o que permite que assumam simultaneamente os lugares de sujeitos e objetos do registro histórico.

2 Dentro do contexto sul-rio-grandense, talvez as principais experiências do gênero tenham sido a Revista Mensal da Sociedade Parthenon Litterario (1869-1879), da principal associação literária do RS no século XIX, a revista Madrugada, publicada por um grupo de escritores modernistas, e a revista Província de São Pedro (19451957), iniciativa da Editora Globo editada por Moysés Vellinho. 
Tendo isso em vista, o presente artigo $^{3}$ busca discutir os processos operados pelos editores do Caderno de Sábado e, assim, entender de que modo eles contribuíram para dar forma à publicação e, simultaneamente, construir a imagem social desse projeto e seu lugar no contexto do jornalismo e da intelectualidade. Ainda que carregue um acento histórico e localizado geograficamente, permite extrapolar o caso particular e contribuir conceitualmente para uma perspectiva mais ampla sobre o lugar de editores e sobre o quanto essa posição está marcada pelas trajetórias individuais e por gestos que, inerentes à função, têm repercussão na construção de um modo de fazer jornalismo cultural - neste caso, notadamente o dos encartes semanais de cultura editados por jornais diários.

\section{SUPLEMENTOS CULTURAIS COMO PROJETOS INTELECTUAIS}

Os suplementos literários e culturais se configuraram no Brasil nos anos 1950 e, enquanto alguns desses encartes enfatizavam a cobertura informativa, noticiosa e imediatista, outros direcionavam a atenção à produção artística em si e à circulação de ideias (ABREU, 1996). Por associarem a cultura à formação do sujeito por meio da leitura e do contato com as letras, artes e humanidades, os suplementos não parecem querer falar a todos os leitores de um jornal. Têm uma especialização proporcional ao seu caráter suplementar dentro do corpo total da publicação.

Nesse sentido, o surgimento do Caderno de Sábado, em setembro 1967, parece uma estratégia do Correio do Povo 4 para alinhar-se a seus pares do centro do país: $O$ Estado de $S$. Paulo e Jornal do Brasil já editavam encartes do gênero desde 1956; e o suplemento Minas Gerais já circulava desde 1966. O jornal porto-alegrense, então, criava aquele que seria um dos quatro principais suplementos semanais de cultura nos anos seguintes e, assim, também se diferenciava de sua concorrência local ao adotar e levar adiante o projeto ${ }^{5}$.

\footnotetext{
${ }^{3}$ Este trabalho parte dos resultados e das reflexões desenvolvidas na tese de doutoramento intitulada "O suplemento cultural como rede de relações: os intelectuais do Caderno de Sábado do jornal Correio do Povo (Porto Alegre, 1967, 1981)", defendida no Programa de Pós-Graduação em Comunicação e Informação da UFRGS. Dela já resultaram recortes mais voltados para a rede formada pelos envolvidos na produção e sua incidência sobre o microclima intelectual porto-alegrense (CARDOSO, 2018) e sobre as trajetórias individuais e a proposta metodológica (CARDOSO, 2019).

${ }^{4}$ O jornal Correio do Povo foi pioneiro no jornalismo empresarial no RS em 1895, quando apenas havia iniciativas político-partidárias do gênero no estado. Em meados do século XX chegou a estar entre os diários de maior alcance e repercussão do país. Desde seu surgimento, manteve estreita ligação com o campo da produção cultural em diversos setores. Exemplar, nesse sentido, foi a existência de uma galeria de arte no prédio do jornal onde ocorriam exposições e recitais de bastante importância na cena local (CARDOSO, 2009).

${ }^{5} \mathrm{O}$ jornal Zero Hora, naquele momento de forte acento popular, iniciara a publicação do Caderno de Cultura em abril de 1967 e o editou até abril de 1970. Em outubro de 1981, ZH voltou a contar com um encarte do gênero. Nesse mesmo ano, o Caderno de Sábado deixaria de ser publicado e seria substituído pelo Letras \& Livros. O
} 
A iniciativa de um suplemento no jornal da Cia. Jornalística Caldas Júnior parece estar ligada ao momento em que Oswaldo Goidanich assumiu a coordenação das páginas de cultura, em 1966. Depois de algumas tentativas em parceria com Paulo Fontoura Gastal de ampliar o espaço para um suplemento sabatino que fosse mais abrangente, foi apenas em setembro de 1967 que o diretor do periódico, Breno Caldas, permitiu que o projeto fosse levado adiante. Tomados de surpresa pela mudança na decisão de Caldas, Gastal e Goidanich organizaram, então, uma edição que reunia seções que já eram veiculadas pelo jornal, material recebido por meio da assinatura de agências de notícias - daí viriam as crônicas de Clarice Lispector - e material recebido de colaboradores - visto que o suplemento não possuía uma equipe própria de trabalho (GASTAL, 1996; GALVANI, 1995; DILLENBURG, 1997).

O então recém-criado Caderno de Sábado circulava com uma média de 16 páginas de tamanho tabloide nas quais eram publicados artigos, ensaios, críticas, crônicas, poemas e textos literários, além de reproduções de obras de arte. $\mathrm{O}$ dia da semana escolhido para a publicação deveu-se à tradição já estabelecida, no Brasil, de suplementos culturais e literários serem editados no fim de semana e à possibilidade de se encaixar no cronograma das oficinas de impressão.

Semestralmente, o suplemento trazia aos leitores um índice de todos os textos publicados categorizados por autores e temáticas. Pode-se, a partir disso, perceber um posicionamento como enciclopédia de saberes a serem acessados no futuro (CARDOSO, 2009) e a tentativa de reforçar vínculo com seus leitores, fiéis a ponto de colecionarem as edições - hábito que deve ter se originado ainda nos folhetins em série publicados no século XIX (SILVA, 1998).

O nome do encarte deixa clara a posição do suplemento: é um caderno à parte do corpo principal do jornal - suplementar - que o abriga e circula aos sábados, dia livre da semana que pode ser ocupado pela leitura mais extensa e aprofundada. Em algo tão explícito como seu nome, é possível deduzir o ideal formativo do suplemento, destinado à ocupação do tempo livre com leitura inteligente. Nesse sentido, o Caderno carrega consigo uma noção de cultura que inclui os ideais de progresso, educação, evolução e razão - típicos do Iluminismo - e a perspectiva de uma formação a partir da elevação do espírito por meio das artes, letras e para as imagens e uma perspectiva marcada pelo consumo. Percebe-se, então, uma redução do caráter enciclopédico contido no projeto editorial anterior (CARDOSO, 2015). Durante os anos 1970, também o Diário de Notícias, do conglomerado Diários Associados, publicou o DN Cultura. Sobre este, há escassas informações. 
humanidades - esta típica do Romantismo. Traduz, portanto, uma ênfase restritiva na formação do sujeito culto, evidenciado em manifestações como a estética, a linguagem e o trabalho intelectual. Posiciona-se como lugar em que o acúmulo de saberes é tanto um objetivo quanto o processo capaz de levar até ele e, assim, meio de distinção social (CARDOSO, 2009).

\section{GESTOS EDITORIAIS E PRESTÍGIO}

Ao pensar sobre as relações estabelecidas pela intelectualidade, Sirinelli (2003) trata de redes de sociabilidade. Para elaborar essa noção, o autor parte da ideia de que todo grupo de homens e mulheres de cultura se organiza ao redor do que ele chama de "sensibilidade ideológica ou cultural comum e de afinidades mais difusas, mas igualmente determinantes, que fundam uma vontade e um gosto de conviver" (p. 248). Essas estruturas constituem, pois, agrupamentos permanentes ou temporários relativamente restritos, como seria o caso de um grupo reunido ao redor de um projeto jornalístico como o Caderno de Sábado.

Essas publicações encartadas nos jornais eram lugares onde se aglutinavam grupos que, nesse espaço editorial, encontravam uma forma de exercer sua influência e de manifestar antagonismos e afinidades (ABREU, 1996). Representavam, assim, a possibilidade de alinhamento a determinado grupo e, portanto, a um ideário objetivado pela publicação: associar-se a esses projetos coletivos tornava-se uma estratégia importante com vistas à consagração - ainda que, em muitos casos, o resultado dessa aposta ainda fosse, naquele momento, completamente imprevisível.

Se intelectuais são criadores e mediadores culturais que, a partir do domínio da escrita, têm suas ideias disseminadas de forma amplificada (BOBBIO, 1997; WILLIAMS, 2000), há uma relevante pergunta a ser feita: quem lhes concede a palavra? Ganham relevo, assim, as modalidades de acesso ao suplemento cultural, marcadas pelas escolhas de seus editores e pelo espaço designado por eles. Estaria, nessa espécie de comporta, o mecanismo que vai ter por resultado o encarte semanal em suas edições isoladas e, depois, na coleção, um conjunto que se constitui como registro da rede que se articulou a partir da publicação e em função dela.

É possível, então, dizer que elemento significativo da composição da lista de nomes vinculados ao suplemento são as finidades existentes entre esses colaboradores e os editores da publicação. Em seus relatos memorialísticos, Gastal (1996) conta que entrou para o 
Correio do Povo, no princípio dos anos 1950, como colaborador - free lancer - por intermédio de Oswaldo Goidanich, a quem chama de grande amigo. Ambos mantinham uma relação de proximidade desde a fundação do Clube de Cinema de Porto Alegre, em 1948. Naquela ocasião, saíram como presidente e vice da entidade.

Oswaldo Goidanich, em sua trajetória, teve atuação em diversas instituições ligadas ao turismo e outras áreas da cultura - com destaque para a ocupação da presidência da Orquestra Sinfônica de Porto Alegre (Ospa). Na Cia. Jornalística Caldas Junior desempenhou diversas funções na redação, além de ter trabalhado na área de promoções e na coordenação de um prestigioso espaço cultural. Paulo Fontoura Gastal, por sua vez, teve atuação primordialmente como crítico de cinema e editor, permanecendo vinculado aos veículos da empresa por mais de 30 anos. A partir de sua atuação, é normalmente descrito figura central da cena cultural sul-rio-grandense. As memórias sobre ele o descrevem como "incentivador", "animador cultural" e "chancela para iniciantes" (CARDOSO, 2009).

Na década de 1960, estiveram envolvidos em mais dois projetos: os festivais de coros do Rio Grande do Sul e a construção do novo Auditório Araújo Vianna ${ }^{6}$. Nos anos 1970, já editores do Caderno de Sábado, foram parceiros na criação e organização do Festival de Cinema de Gramado - cuja primeira edição ocorreu em 1972 -, e integraram a Comissão Especial de Estudos de Levantamento e Preservação do Patrimônio Histórico, Artístico e Cultural do Rio Grande do Sul. Ocupantes de posições importantes na articulação, na organização e na administração da cena cultural porto-alegrense e de posições privilegiadas no jornal de maior importância do Rio Grande do Sul, ambos os jornalistas contribuíram para a imagem do projeto que coordenaram a partir de 1967.

O suplemento cultural do Correio do Povo, então, pelas mãos de seus editores acumulou capital simbólico que lhe assegurou uma melhor posição dentro do contexto local e, assim, pôde atrair uma quantidade maior de intelectuais consagrados e mesmo novatos. A presença dos já proeminentes editores, pois, permitiu arregimentar indivíduos que, vinculados à organização e à produção cultural na cidade, também tinham seu prestígio. Lucro simbólico, portanto, para o suplemento e para o jornal - num processo de atração de portadores de capital simbólico que ao mesmo tempo por aí estarem também almejavam posicionar-se socialmente.

\footnotetext{
${ }^{6} \mathrm{O}$ Auditório Araújo Vianna originalmente estava situado às margens da Praça Marechal Deodoro, no Centro Histórico de Porto Alegre. Em 1964, para dar lugar à construção do novo edifício da Assembleia Legislativa do Rio Grande do Sul, foi transferido para o Parque Farroupilha - conhecido também como Parque da Redenção.
} 
Goidanich e Gastal, então, consistiram em peritos que, pela posição que ocupavam na imprensa, detinham o poder de selecionar os nomes que comporiam o rol de intelectuais presentes no CS. Autoridades legitimadas, selecionavam os indivíduos cujas palavras fariam ressoar por meio da publicação que coordenavam. Fizeram do projeto do Caderno de Sábado, portanto, uma estratégia coletiva que incluía muitos indivíduos que tiveram a imprensa como lugar de circulação de seu pensamento e de acúmulo de capital simbólico que lhes serviria como forma de posicionamento dentro dos microcosmos específicos de suas profissões e, ainda, no contexto social mais amplo da cidade e do país.

Em depoimento concedido a Dillemburg (1997), Oswaldo Goidanich rememora o quanto ele e o colega de redação estavam preocupados com a quantidade de trabalhos recebidos na redação do Correio do Povo e que, por falta de espaço, não podiam publicar. O jornalista conta:

Paulo Fontoura Gastal, crítico de cinema e editor da página diária de notícias culturais, sofria junto comigo. Gastal, apesar do seu temperamento irascível, escondia um coração de ouro e os moços intelectuais confiavam nele. Ele os atraía como o mel atrai a abelha operária. Ambos sonhávamos em substituir as páginas literárias por um verdadeiro suplemento que fosse mais abrangente no enfoque dos fatos culturais e servisse, sobretudo, à revelação de novos valores para as letras e as artes do Rio Grande do Sul (p. 134-135).

Também é marcante o relato de P. F. Gastal a seu filho Ney Gastal, quando trata do processo de seleção de textos para o suplemento e que, de alguma forma, permitia o estabelecimento de vínculos com o Caderno de Sábado.

Ney Gastal: Sair em suas páginas era uma disputa concorridíssima, e havia toda uma mitologia sobre a composição da comissão de seleção que escolhia quem seria e quem não seria publicado. Já se pode falar nisto?

P. F. Gastal: Acho que sim. Eu procurava ouvir as pessoas. Em termos de poesia, por exemplo, tinha na redação um cara muito bom, que era o Pio de Almeida. Tinha também o Paulo de Gouvêa, que era ótimo para ajudar a selecionar os poetas. Mario Quintana, coitado, levava a fama, ouvia broncas dos poetas não publicados, mas não participou nunca do processo. No máximo e poucas vezes, trazia um recomendado, que, é claro, era publicado. Guilhermino Cesar participava mais. Mas não havia uma comissão formalmente constituída. No fundo a edição toda era feita no peito e na raça, até porque não havia muito tempo para digressões. Dezesseis páginas por semana, em tabloide, não é pouca coisa. E houve vezes, em edições especiais, que foram muito mais. O Caderno chegou a sair com trinta e duas páginas. Foi uma experiência única, que além de publicar contistas, poetas, historiadores, ensaístas e por aí afora, ainda trazia, toda semana, na capa, uma obra de artista plástico gaúcho, servindo para divulgar e lançar muita gente (GASTAL, 1996, p. 259).

Considerando a posição regionalmente hegemônica ocupada pelo Correio do Povo, quando os editores escolhiam quem figuraria nas páginas do suplemento, de alguma forma 
atribuíam a si mesmos um poder simbólico no processo de consagração da intelectualidade, sobretudo a sul-rio-grandense. Essa ambição fica clara em diversas manifestações editoriais ${ }^{7}$ presentes nas páginas das edições: sinalizam uma intenção de reforçar a qualidade do suplemento e seu papel no cenário cultural e também o mérito e a posição de seus colaboradores enquanto pensadores e produtores artísticos (CARDOSO, 2010).

Distribuidores de cultura em sentido estrito (LIPSET, 1959), Goidanich e Gastal, portanto, têm na imprensa um espaço socialmente valorizado a partir de onde podem fazer repercutir as ideias da intelectualidade. Editores, selecionavam autores e textos segundo critérios que - ainda que ponderáveis - estavam marcados por suas preferências e crenças: uma ideia de cultura muito ligada à formação enciclopédica do indivíduo a partir da aquisição de um recorte de saberes consagrados, o que tem efeitos socialmente distintivos (CARDOSO, 2009).

Inserido o suplemento no conjunto dos aparatos comunicativos do campo intelectual, a ação dos editores teve efeito sobre os processos de organização das práticas dos letrados e, assim, incidiu sobre os modos de atuação e competição desses sujeitos tanto em seus círculos mais restritos quanto na realidade social mais ampliada. Brunner e Flisfisch (1983) apontam o quanto a dificuldade de acesso ao mesmo tempo pode tornar uma publicação mais prestigiosa e pode torná-la forma de consagração mais valiosa e, por isso, mais almejada. Nesse sentido, os editores detêm o típico poder do jornalismo de nomear e excluir simbolicamente a partir da concessão de espaço e das dimensões e características deste.

\section{UMA SELETA REDE DE RECONHECIMENTO}

Para se pensar de modo mais detalhado sobre as trajetórias colaboradores do suplemento - os escolhidos pelos editores, portanto -, realizou-se um estudo a partir do conjunto composto pelos dez autores mais frequentes na coleção ${ }^{8}$. Esse grupo corresponde muito ao perfil dos colaboradores identificados por Abreu (1996) nos suplementos editados na década de 1950, quando este gênero de publicação atingiu seu auge no Brasil: eram

\footnotetext{
${ }^{7}$ Como, na publicação, não há um espaço editorial propriamente dito, o estudo dos sentidos que o Caderno de Sábado constrói sobre si mesmo foi conduzido a partir de uma Análise de Discurso - seguindo a proposta de Benetti (2007) - a partir de 41 textos que incluíam pequenas "notas de redação" que falam diretamente ao leitor, apresentações de novas sessões e séries de artigos, além das páginas comemorativas ao primeiro e segundo aniversários.

${ }^{8}$ Para se chegar a esses dez nomes, realizou-se um levantamento da autoria de todos os 11.144 textos presentes nas 646 edições do CS - o número total de autores catalogados se aproxima de 2.000. A partir daí, levou-se adiante uma Análise de Conteúdo dos 3.029 textos desses dez autores, categorizando-os a partir de seus gêneros, temas e referências geográficas e temporais (CARDOSO, 2016).
} 
predominantemente homens ligados à literatura, à academia, ao serviço público e tinham no jornalismo uma forma de reconhecimento social na função de intelectual, o que lhes permitia reconverter essa visibilidade em capital social e cultural.

Se tomado o Caderno de Sábado como espaço de circulação da intelectualidade - com predomínio absoluto dos atuantes em Porto Alegre -, pode-se dizer que a cooptação executada pelos editores Gastal e Goidanich, de alguma forma, dava preferência aos agentes já consagrados. Moysés Vellinho e Guilhermino Cesar, por exemplo, eram sujeitos cujo prestígio vinha sobretudo de uma atuação como organizadores e incentivadores da produção cultural no Rio Grande do Sul em espaços e instituições de diversas naturezas.

Surgem, também, escritores que - intelectuais criativos - mobilizavam capital simbólico para o encarte por meio de suas assinaturas ao mesmo tempo que atraíam a atenção de um público mais diversificado em razão de sua circulação mais ampla e de sua popularidade naquele momento - Mario Quintana e Clarice Lispector como principais exemplos; ela, a única mulher do grupo.

Entre os homens de imprensa, vê-se o cruzamento de duas gerações: daqueles forjados na própria prática da redação - Paulo de Gouvêa -; e daqueles que, jovens, traziam consigo o capital cultural institucionalizado representado pela formação universitária em Jornalismo e que, nos anos 1970, era considerado meio de acesso à prática profissional nessa área Antonio Hohlfeldt e Ney Gastal.

Ainda, representados por Francisco Riopardense de Macedo, ganham espaço os docentes e pesquisadores que empreenderam carreira acadêmica de forma mais sistemática e usaram esse espaço do jornal como modo de ampliar o público leitor de sua produção. Finalmente, também estão presentes sujeitos que, diletantes e por seus perfis e formações específicos, atuam como mediadores entre a produção literária e cultural e o público - papel este exercido com ênfase por Herbert Caro, em crônicas sobre música de concerto, e por Paulo Hecker Filho, na crítica literária.

Sobrevivia, no entanto, uma cultura de certo amadorismo na execução do suplemento: a narrativa mais frequente é de que não havia remuneração pelo trabalho; e nenhum dos profissionais com vínculo com a Companhia Jornalística Caldas Junior estava plenamente dedicado a essa tarefa - eram seis entre os dez aqui analisados. Todos tinham, na redação do Correio do Povo, funções como editores - Gastal e Goidanich -, repórteres - Ney Gastal e Hohlfeldt - ou secretário de redação - Gouvêa. Não eram remunerados, portanto, pelas tarefas 
ligadas ao encarte semanal. Diferente relação trabalhista com a empresa tinha Mario Quintana: era pago para ser "o poeta do jornal”, ou seja, não tinha nenhuma obrigação fixa, além de sua coluna semanal.

Nessa rede, portanto, estavam incluídos agentes atuantes nos circuitos da escrita - o sistema literário, o mercado editorial, a imprensa e mesmo a academia -, no Estado e com participação anterior em projetos editoriais e movimentos do campo da produção cultural local - principalmente os modernistas. Percebe-se, assim, um predomínio de nomes associados a esferas de poder de diversas ordens - sobretudo político e simbólico - do Rio Grande do Sul e mesmo nacionais.

Nesse sentido, o Caderno de Sábado se constituiu como uma espécie de retrato, ainda que recortado e parcial, do campo intelectual porto-alegrense. Em suas páginas aparecem simultaneamente o antes pujante mercado de produção editorial representado pela Editora Globo, um conjunto de instituições organizativas e associativas de intelectuais que se estabeleceram na cidade de forma independente - caso do Instituto Histórico e Geográfico do Rio Grande do Sul - e, ainda, um sistema de organização, gestão e fomento da cultura que se estruturava a partir do Estado, o que já vinha se estabelecendo a partir dos anos 1950.

Nesse sentido, a rede de sociabilidade que, a partir de 1967, foi articulada pelos editores ao redor do Caderno de Sábado consistiu em mais um agrupamento temporário de intelectuais no contexto porto-alegrense - ainda que não transitório ou breve, já que foram quase 14 anos de publicação ininterrupta. É possível inferir, portanto, que parte significativa do prestígio angariado pela publicação seja decorrente dessa projeção do campo de produção intelectual e cultural que se entrevê no projeto editorial encabeçado por Gastal e Goidanich. Nesse sentido, o suplemento e os responsáveis pela sua elaboração foram - aparato e agentes individuais - participantes do processo de estabelecimento da intelectualidade sulina durante o período em que o $C S$ circulou.

\section{UM SISTEMA DE CLASSIFICAÇÃO}

A partir do momento em que se constitui, ao redor de uma publicação, essa rede de intelectuais - recrutados e como tal reconhecidos - ainda ocorre um processo que diferencia esses indivíduos entre si. São, pois, estratificados. Entre os gestos editoriais que denotam seleção e estratificação, no $C S$, está a concessão de colunas designadas por um nome específico: Do Caderno H, de Mario Quintana; Os melhores discos clássicos, de Herbert 
Caro; e M.P./Discos, de Ney Gastal. Quatro outros autores acabaram por ocupar espaços fixos na maior parte de seus textos: Guilhermino Cesar, Paulo de Gouvêa, Clarice Lispector e Francisco Riopardense de Macedo - vários ensaios e artigos, inclusive organizados em longas séries com textos publicados semanalmente.

A presença constante desses sujeitos criava, assim, para o público, uma expectativa de encontro semanal e regular; dessa forma, fortalecia-se um laço de fidelidade. Nesse sentido, já se pode perceber o quanto a esses intelectuais estava vinculada uma ideia de que poderiam associar ao suplemento um tipo de valor: semanalmente aquela assinatura se apresentaria aos leitores. Nesse sentido, transparece um atribuição de valor a esses agentes por parte dos editores e que se reflete nesse processo de valorização do espaço concedido.

Pode-se dizer, ainda, que outro espaço usado pelos editores para distinguir os colaboradores uns dos outros em termos de prestígio eram os trechos de textos destacados como epígrafes no cabeçalho da capa de cada edição: Guilhermino Cesar, Paulo de Gouvêa, Mario Quintana e Clarice Lispector têm destaque no conjunto, ainda que todos os dez autores estudados apareçam pelo menos uma vez. Graficamente, esse lugar prestigioso está metaforicamente construído nas capas dos suplementos: no cabeçalho figuram os nomes do Correio do Povo e do Caderno de Sábado e uma frase retirada de um texto publicado no interior do suplemento e escolhida para aparecer em destaque, bem como o respectivo autor. A cada semana, apresentam-se, nesse espaço nobre, o jornal, o suplemento, o texto e o intelectual.

No caso do texto, especificamente, há um caráter duplo: como conteúdo, traz para destaque um pensamento tido como relevante e digno de mérito; como forma, denota a associação imediata da intelectualidade à palavra escrita e ao domínio da produção textual qualificada - estas em geral condições históricas para a ocupação da posição social como intelectual. Juntas, essas ideias representadas pelos elementos gráficos estabelecem entre si um jogo de associações que parece querer intercambiar capital simbólico entre as instituições, agentes e campos que representam. Nesse sentido, a aproximação do Correio do Povo, por meio do Caderno de Sábado, com intelectuais é uma relação que se estabelece entre as posições ocupadas por esses sujeitos e agentes dentro de seus campos de origem e, em última instância, expressa uma relação entre os campos (BOURDIEU, 2005).

Segundo Gomis (1991), fontes, jornalistas e audiência coexistem em um mesmo sistema; no caso do suplemento, pode-se inferir que os intelectuais - aqui incluídos tanto os 
autores de textos quanto os próprios editores - escreviam e publicavam também uns para os outros, já que também entre eles circularia o suplemento. Isso coloca o encarte como um intermediário nesse sistema na medida em que contribuía para a visibilidade e o consequente acúmulo de poder simbólico dos sujeitos criadores ao dar-lhes voz. No caso específico do Caderno de Sábado, nas edições especiais em que esses intelectuais eram homenageados e se homenageavam uns aos outros, há indício da hierarquização desses sujeitos por parte dos editores - ainda que não seja possível estabelecer o nível de intencionalidade por trás desses gestos.

Entre os distinguidos com esse espaço, destacam-se, até mesmo pelo viés mais característico do suplemento, os nomes vinculados à produção literária (CARDOSO, 2009): há agentes notórios internacional e nacionalmente. Entre aqueles que atuavam no Rio Grande do Sul, estavam nomes já muito consagrados como Vianna Moog, Raul Bopp, Cyro Martins, Alcides Maya, Eduardo Guimaraens, Augusto Meyer - em duas ocasiões -, Simões Lopes Neto e Erico Verissimo - este o grande destaque, já que foi homenageado em seis edições consecutivas logo após a sua morte. Também mereceram essa distinção três dos autores entre os dez mais frequentes na coleção: Mario Quintana, Guilhermino Cesar e Moysés Vellinho.

Se tomados esses nomes, sobretudo com relação àqueles ligados às letras sul-riograndenses, é possível dizer que está constituído uma espécie de panteão. Ao construir esse lugar de destaque, o suplemento acaba por posicionar-se como instância legitimadora e, assim, participa do processo de estabelecimento do cânone literário sulino. Sendo o jornalismo também uma forma de documentação da realidade - ao mesmo tempo que a constrói -, para o futuro estariam registrados, a partir do que fora publicado no suplemento, os nomes que merecem ser perpetuados.

\section{CONSIDERAÇÕES FINAIS}

P. F. Gastal e Oswaldo Goidanich, típicos homens de imprensa forjados na primeira metade do século XX, exerceram dentro da Caldas Júnior diferentes posições na cadeia produtiva do jornalismo e, por isso, já tinham prestígio nesse no momento em que iniciaram, em 1967, o projeto do Caderno de Sábado. Por suas frequentes e marcantes participações em eventos e instituições do campo da produção cultural da cidade - inclusive em parceria, em alguns casos, e congregando-se com outros homens e mulheres de letras que depois viriam a colaborar com seu projeto editorial -, já possuíam trânsito que lhes assegurava reconhecimento pela intelectualidade porto-alegrense. Usando esse prestígio, buscaram reunir 
um grupo de participantes ativos e notórios que contribuíram para que se consagrasse historicamente a imagem que o Correio do Povo buscava construir e fixar desde sua fundação como um reduto de intelectuais (GALVANI, 1995).

Essa intelectualidade ligada ao suplemento - recrutada, reconhecida e classificada pelos editores - orbitava ao redor do projeto e conformava uma rede que, documentada na coleção do CS, permite entrever um sistema ações e de relações entre agentes - indivíduos, agrupamentos e instituições - que se articulavam e influenciavam. Integravam, constituíam e perpetuavam, assim, um aparato legitimador que teve participação ativa na organização do campo intelectual sul-rio-grandense. Para Gastal e Goidanich, isso representou lucro simbólico obtido a partir de uma ação ativa como mentores desse projeto: também eles ficaram reconhecidos como intelectuais.

Uma publicação é a combinação de uma existência concreta - neste caso, a coleção de edições que foram publicadas, circularam e depois de tornaram documento - com o emaranhado de sentidos resultantes do contato de indivíduos com esse objeto ou com o que se diz sobre ele. Sendo assim, este estudo dos processos editoriais que deram origem ao Caderno de Sábado como suplemento em si e ao conjunto de narrativas desencadeadas a partir dele é uma forma de contribuir para a fixação de um imaginário ao redor da publicação e de seus editores que guarde proximidade com indícios da realidade.

E se o que se estabelece como "história" é um conjunto de narrativas que, a partir de processos múltiplos de disputas, resulta como uma síntese que ganha força simbólica e assume a posição dominante, um trabalho desta natureza contribui para que se possam esmiuçar papéis e processos. É possível, a partir disso, trazer à tona o quanto as frações ocupantes de posições dominantes na sociedade fazem avançar e se alastrar uma memória seletiva que traz consigo personagens, projetos, episódios e designativos que lhes servem ao mesmo tempo de substrato para legitimação e de forma de autoafirmação ante o restante da do corpo social. Dentro do campo jornalístico, o resultado disso é a instituição de imagens e modos de ação que se tornam referências para aqueles que vêm depois.

O caso do ressurgimento do Caderno de Sábado, nesse sentido, é emblemático. Ainda que adaptado ao contexto e aos formatos deste século, busca emular muito do que constituía seu antecessor homônimo. Mesmo que tenha sido preciso incorporar o que antes não se encontraria em um suplemento - como horóscopo, programação televisiva e coluna social, elementos estes mais característicos das editorias diárias de cultura -, ainda traz alguns traços 
típicos de seu antecessor, como a direção por uma equipe editorial composta por agentes que trazem capitais acumulados tanto no jornalismo quanto em outras instâncias - notadamente a academia. Da mesma forma, estão presentes a publicação de textos assinados por nomes consagrados, o espaço maior para reflexão do que o concedido no caderno principal do jornal e um recorte temático com viés reflexivo.

\section{REFERÊNCIAS}

ABREU, Alzira Alves. Os suplementos literários: os intelectuais e a imprensa nos anos 50. In: ; MATTMAN-WELTMAN, Fernando; FERREIRA, Marieta de Moraes; RAMOS, Plínio de Abreu. (orgs.) A imprensa em transição: o jornalismo brasileiro nos anos 50. Rio de Janeiro: Ed. Fundação Getúlio Vargas, 1996. p. 13-60.

BOBBIO, Norberto. Os intelectuais e o poder: dúvidas e opções dos homens de cultura na sociedade contemporânea. São Paulo: Unesp, 1997.

BOURDIEU, Pierre. A distinção: crítica social do julgamento. São Paulo: Edusp; Porto Alegre: Zouk, 2007.

A economia das trocas simbólicas. São Paulo: Perspectiva, 2005.

BRUNNER, José Joaquín; FLISFISCH, Angel. Los intelectuales y las instituciones de la cultura. Santiago: FLACSO, 1983.

CARDOSO, Everton. Bom gosto e prestígio em um suplemento cultural: a lógica o Caderno de Sábado do Correio do Povo em seu próprio discurso (Porto Alegre, 1967-1981). Conexão Comunicação e Cultura, Caxias do Sul, v. 9, n. 18, p. 133-147, jul-dez 2010.

. Do projeto enciclopédico ao guia de consumo: os modelos de suplemento semanal de cultura do Caderno de Sábado (1967) e do Letras \& Livros (1981) do jornal Correio do Povo (Porto Alegre). In: ENCONTRO NACIONAL DE PESQUISADORES EM JORNALISMO, 13., 2015, Campo Grande. Anais... Campo Grande: Associação Brasileira de Pesquisadores em Jornalismo, 2015.

Enciclopédia para formar leitores: a cultura na gênese do Caderno de Sábado do Correio do Povo (Porto Alegre, 1967-1969). 2009. Dissertação (Mestrado em Pós Graduação em Comunicação e Informação) - Programa de Pós-graduação em Comunicação e Informação, Universidade Federal do Rio Grande do Sul, Porto Alegre, 2009.

O suplemento cultural como rede de relações: os intelectuais no Caderno de Sábado do jornal Correio do Povo (Porto Alegre, 1967-1981). 2016. Tese (Doutorado em Pós Graduação em Comunicação e Informação) - Programa de Pós-graduação em Comunicação e Informação, Universidade Federal do Rio Grande do Sul, Porto Alegre, 2016.

; GOLIN, Cida. Enciclopédia para formar leitores: a cultura na gênese do Caderno de Sábado do Correio do Povo (Porto Alegre, 1967-1969). Galáxia, São Paulo, n. 18, p.137-151, dez. 2009.

O Caderno de Sábado do Correio do Povo como articulador de uma rede: o microclima intelectual de Porto Alegre em um suplemento cultural (1967-1981). In: BALDISSERA, Rudimar; BENETTI, Marcia. Pesquisa e perspectivas em Comunicação e Informação. Porto Alegre: Sulina, 2018. p. 152-168. 
; __ Os intelectuais no Caderno de Sábado do Correio do Povo: prestígio e memória em um suplemento cultural. In: RÊGO, Ana Regina et. al. (orgs.). Os desafios da pesquisa em história da comunicação: entre a historicidade e as lacunas da historiografia. Porto Alegre: Edipucrs, 2019. p. 471-499.

DILlenbURG, Sérgio Roberto. Correio do Povo: história e memórias. Passo Fundo, RS: Ediupf, 1997.

GALVANI, Walter. Um século de poder: os bastidores da Caldas Júnior. 2.ed. Porto Alegre: Mercado Aberto, 1995.

GASTAL, Ney. Uma vida em três amores. In: GASTAL, P. F. Cadernos de cinema de P. F. Gastal. Porto Alegre: Unidade Editorial, 1996. p. 251-266.

GOMIS, Lorenzo. Teoría del periodismo: cómo se forma el presente. Barcelona: Paidós, 1991.

LIPSET, Seymour Martin. American intellectuals: their politics and status. Daedalus, Massachussetts, v. 88, n. 3, p. 460-486, summer 1959. Disponível em: <

http://www.jstor.org/stable/20026515?seq=1\#page_scan_tab_contents>. Acesso em: 20 fev 2020.

LOPES, Luiz Gonzaga. “O Caderno de Sábado era uma espécie de fórum literário". Livros A+, Porto Alegre, 2 mar 2014c. Disponível em: <http://www.correiodopovo.com.br/blogs/livrosamais/?p=367. Acesso em: 4 abr 2020.

PEREIRA, Fábio. Jornalistas-intelectuais no Brasil. São Paulo: Summus, 2011.

SILVA, Wilsa Carla Freire da. Cultura em pauta: um estudo sobre o Jornalismo Cultural. 1998. Dissertação (Mestrado em Ciências da Comunicação) Universidade de São Paulo, Programa de PósGraduação em Ciências da Comunicação, 1998.

SIRINELLI, Jean-François. Alain e les siens: sociabilité du milieu intellectuel e responsabilité du clerc. Revue française de science politique, ano 38, n. 2, p. 272-283, 1988.

. As elites culturais. In : RIOUX, Jean-Pierre ; . Para uma história cultural. Lisboa : Estampa, 1998. p. 259-279.

. Le hasard ou la nécessité ? Une histoire en chantier : l'histoire des intellectuels. Vingtième Siècle : revue d'histoire, Paris, v. 9, n. 1, p. 97-108, 1986.

. Os intelectuais. RÉMOND, René. Por uma história política. 2. ed. Rio de Janeiro: FGV, 2003. P. 231-269.

WILLIAMS, Raymond. Cultura. 2. ed. Rio de Janeiro: Paz e Terra, 2000. 
Jornalista e doutor em Comunicação e Informação (PPGCOM/UFRGS). Atua como editorchefe do Jornal da Universidade/UFRGS, professor no curso de Jornalismo da Unisinos e crítico independente de ópera e espetáculos.

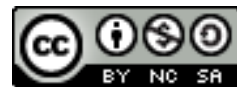

Esta obra está licenciada com uma Licença Creative Commons Atribuição-NãoComercial-CompartilhaIgual 4.0 Internacional 